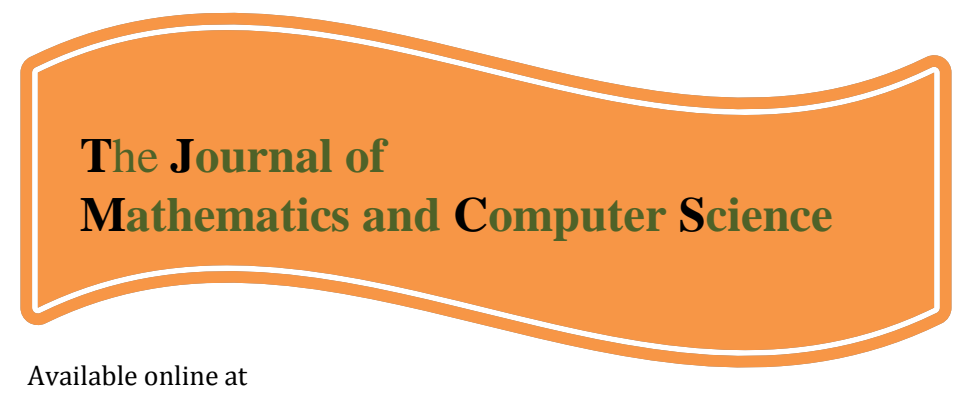

\title{
http://www.TIMCS.com
}

The Journal of Mathematics and Computer Science Vol .5 No.3 (2012) 167-175

\section{Manor for control of the car park using fuzzy logic}

\author{
Jamal Ghobadi dizaj yekan \\ Khorasan Institute of Higher Education, Mashhad, Iran \\ Jamal_Ghobadi@yahoo.com \\ Amin Adineh Ahari \\ Khorasan Institute of Higher Education, Mashhad, Iran \\ Aadinehahari@yahoo.com \\ Seyed Kamaleddin Mousavi Mashhadi \\ University of Science and Technology, Faculty of Electric Engineering, Tehran, Iran \\ Sk_Mousavi@iust.ac.ir
}

Received: February 2012, Revised: November 2012

Online Publication: December 2012

\begin{abstract}
In this article we have tried to control your car and park it was good. the car park there are different methods such as using fuzzy controller, genetic algorithm, neural networks, image processing, sensors and .... use In this paper, fuzzy control method is used. Park for three types of controllers is proposed in this paper. for park in the rear and park in front of the fuzzy controller if the primary controller having a first car or the car park for the start of the second controller in the output. the second controller uses the vehicle away from the table and change the angle of rotation angle of the car makes the car move. park is also only a single controller for the vertical input, single output is used to move the vehicle entrance and exit angle of the vehicle steering angle is changed. this has the advantage over other papers that extra controller to start the car park used in most papers on this subject has been addressed.
\end{abstract}

Keywords: Estimated, The rules, Fuzzy controller, Parallel Park The membership

\section{Introduction.}

In recent years, automated car park has attracted the attention of researchers. in the classic method using charts or diagrams Dubin Reed \& Sheep are paid to solve such problems. articles in this issue has been much recent decades. organizations and laboratories as well as pursue advanced research in this field. in the car park and had a wider range of areas such as drainage and storage or transport of disabled persons and mooring of vessels at the jetty to be pointed. the car park is actually putting the vehicle parallel to the direction of their movement in a confined space 
that is larger than the dimensions of the vehicle. in general, a control system kinematic equations with nonlinear constraints is difficult and varies with time so as to be automatically performed while a person using a series of simple rules can easily make a car park. human behavior with regard to available space is one of the following may occur. if not enough parking space to park does not occur. when is enough parking space to park occurs. thus, the geometric path planning based on fuzzy logic for a particular soft computing is proposed to solve the parking problem. the proposed works can be fuzzy in some way based on fuzzy neural networks and genetic algorithm with fuzzy controller using Several fuzzy controller into. many articles in the park have been proposed based on fuzzy basis, each with a different input or output to the steering angle by using a Sugeno fuzzy inference or obtain or anfis used for vehicle control . in [17], a controller using fuzzy inference to obtain input from the table of distances and angles of rotation of the vehicle wheel is used for parks. our method is similar to that of a controller for use when the vehicle is parked. in [18] first determine the location of the park began using Petri networks starting location of the appropriate park Then using the fuzzy controller to park the vehicle speed is constant The controller has a duty to use the first two angles, the angular rotation rate of the proposed decree. The second controller also has a duty to the rotation rate of the controller 1 and the final point of comparison between high and low to make the rotation. in [19] to control the steering angle so that the wall is a fixed distance or purpose ie it is parallel with the wall of a single-input ssingle-output controller is used to obtain the deduction.

in [20] using fuzzy network controller, the output angle of the vehicle is determined in this way Sugeno model is used and control of a positioning sensor, ultrasonic sensor, and three vehicles used.

\section{Car model:}

automotive equivalent of a page that was parallel to the rear wheels and will only be able to slip. the front wheels can be -45 and +45 will change.

\section{Table variables and symptoms:}

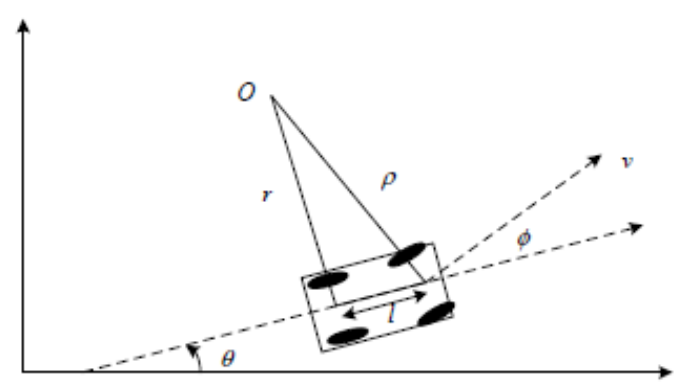

Fig 1 - Vehicle models from paper [18]

Table 1 - variables and symptoms

\begin{tabular}{|l|l|}
\hline$\left(x_{f}, y_{f}\right)$ & center position of the front wheels \\
\hline$\left(x_{r}, y_{r}\right)$ & center position of the rear wheels \\
\hline$\phi$ & $\begin{array}{l}\text { rotation angle of the steering wheel or front wheel } \\
\text { changes }\end{array}$ \\
\hline $\mathrm{i}$ & the distance between the front and rear axle \\
\hline$O$ & curvature center \\
\hline$\theta$ & $\begin{array}{l}\text { the angle between the axis of the vehicle with the } \\
\text { x axis }\end{array}$ \\
\hline$\rho$ & $\begin{array}{l}\text { distance from front axle to center of curvature } \\
\text { center of the vehicle }\end{array}$ \\
\hline$r$ & radius of curvature \\
\hline$v$ & front wheel speeds \\
\hline
\end{tabular}




\section{Model relationship:}

$\dot{x}_{r}=v \cos \theta \cos \phi$

$\dot{y}_{r}=v \sin \theta \cos \phi$

$\dot{\theta}=v \frac{\sin \phi}{l}$

assumptions and limitations: primary location where the car should be about 5 times the length of the vehicle is parked and the car park is at least 2 car lengths. the vehicle speed is constant. changes in steering angle between -30 and +30 degrees.

\section{Parallel park a car from the front:}

of the 2 fuzzy controller is used for parks.

controller 1: this controller is used to start the second controller. this controller is a single input and single output. the input of the controller of the table $(\mathrm{y} 0)$ and output the longitudinal position for the start of the second controller (xsc).

controller 2: this controller is used for both input $(\theta, \mathrm{y})$ and output $\phi$ variables.

controller 1: the membership functions and rules table is as follows .it is worth mentioning that the experimental values of membership functions are calculated.
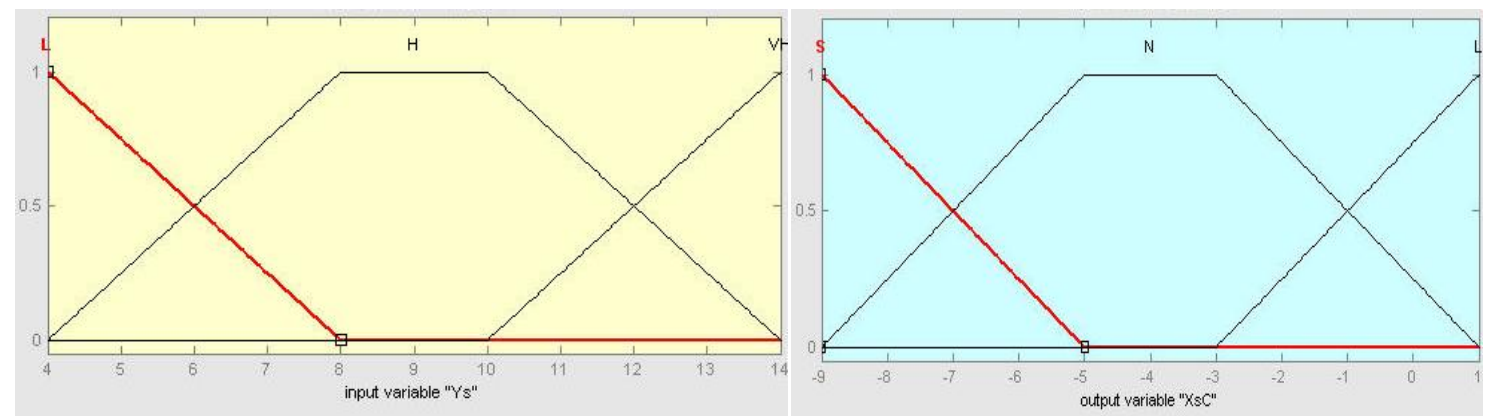

Fig 2: membership function of input and output controller 1

table 2 - table 1 controller rules

\begin{tabular}{|l|l|l|l|}
\hline Ys & L & H & VH \\
\hline XsC & L & N & S \\
\hline
\end{tabular}
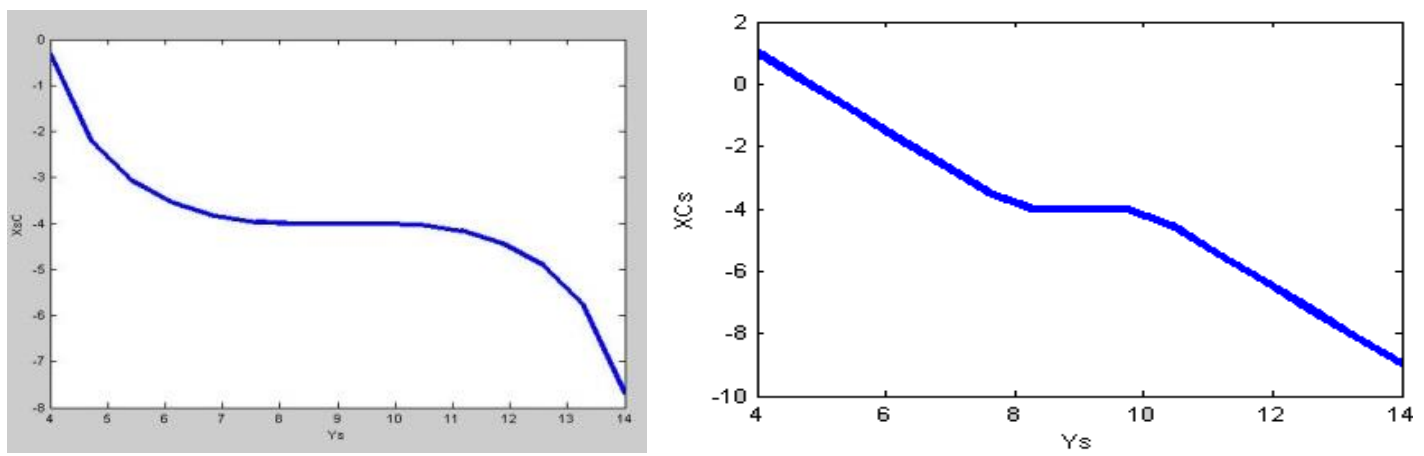

Fig 3: surface controller 1 in the state mamdani and sugeno

\section{Equation coefficients for the surface to the top:}

the equation obtained equation with coefficients in Figures 3 are shown in Table 3. 
J. Ghobadi, A. Adine, S.K. Mousavi / TJMCS Vol .5 No.3 (2012) 167-175

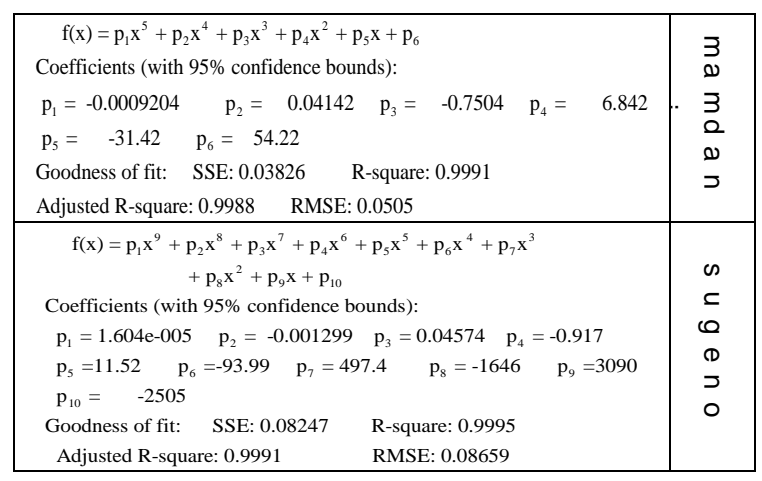

Table 4 - Comparison of estimated values with actual values for controller 1

\begin{tabular}{|l|l|l|l|l|}
\hline Input & $\begin{array}{l}\text { real } \\
\text { (mamdani) }\end{array}$ & $\begin{array}{l}\text { estimated } \\
\text { (mamdani) }\end{array}$ & $\begin{array}{l}\text { real } \\
\text { (sugeno) }\end{array}$ & $\begin{array}{l}\text { estimated } \\
\text { (sugeno) }\end{array}$ \\
\hline 6 & 3.49 & -3.545 & -1.5 & -1.436 \\
\hline 8 & -4 & -3.9613 & -4 & -3.86 \\
\hline 10 & -4 & -4.038 & -4 & -4.139 \\
\hline 12 & -4.51 & -4.455 & -6.5 & -6.564 \\
\hline 14 & -7.7 & -7.654 & -9 & -8993 \\
\hline
\end{tabular}
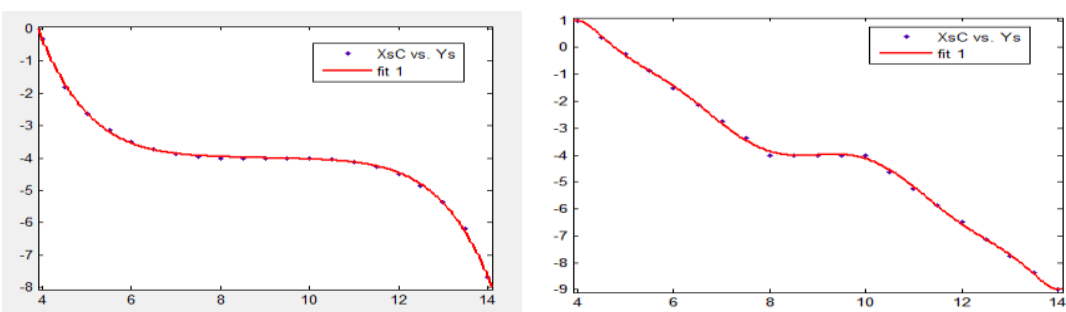

Fig 4: the equation obtained for controller 1 in the state mamdani and sugeno

\section{Controller 2:}

Input Y: this input is defined as below and how the membership functions as follows.

Input $\boldsymbol{\Theta}$ : the input angle is below the range of the vehicle and how the membership functions as follows.
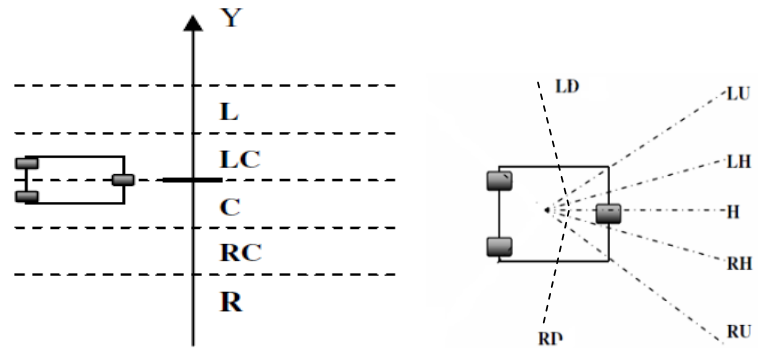

Fig 5- view from the scope of Article [17]
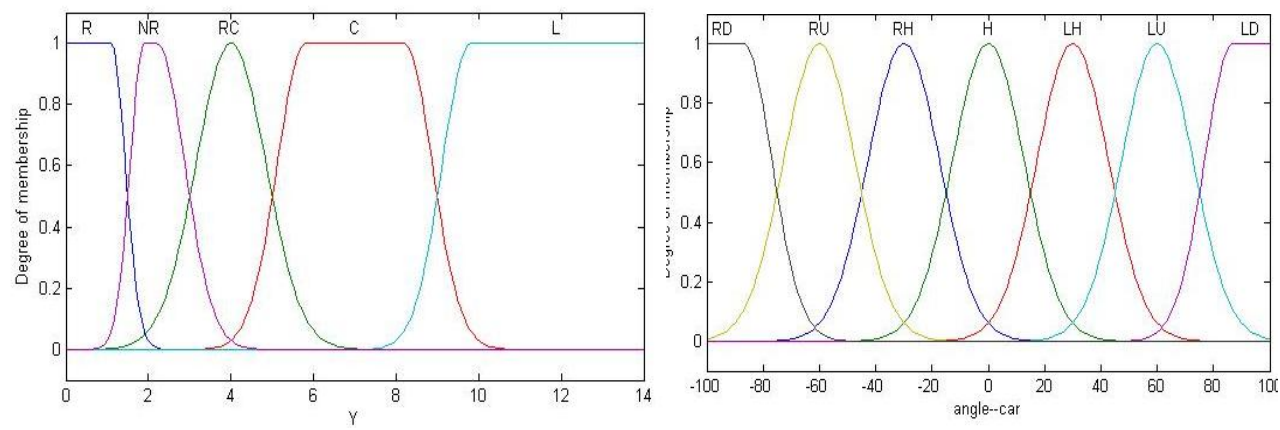

Fig 6: view the membership functions for $Y$ and $\boldsymbol{\theta}$ 
Output $\phi$ : The output of the wheel changes, and its membership function is as follows.

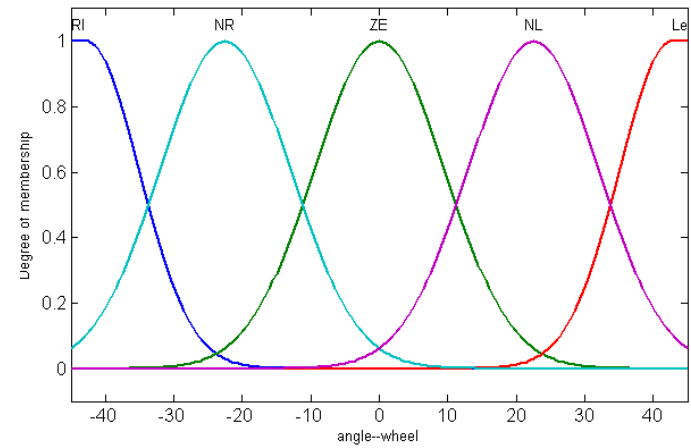

Fig 7: View the membership functions $\phi$

Table 5 - Table rules controller 2

\begin{tabular}{|c|c|c|c|c|c|c|c|}
\hline & RD & RU & RH & H & LH & LU & LD \\
\hline L & NL & ZE & NR & NR & Ri & Ri & Ri \\
\hline C & NL & ZE & NR & RI & Ri & Ri & Ri \\
\hline RC & Le & NL & ZE & NR & Ri & Ri & Ri \\
\hline NR & Le & Le & NL & ZE & NR & Ri & Ri \\
\hline R & Le & Le & Le & NL & ZE & NR & Ri \\
\hline
\end{tabular}
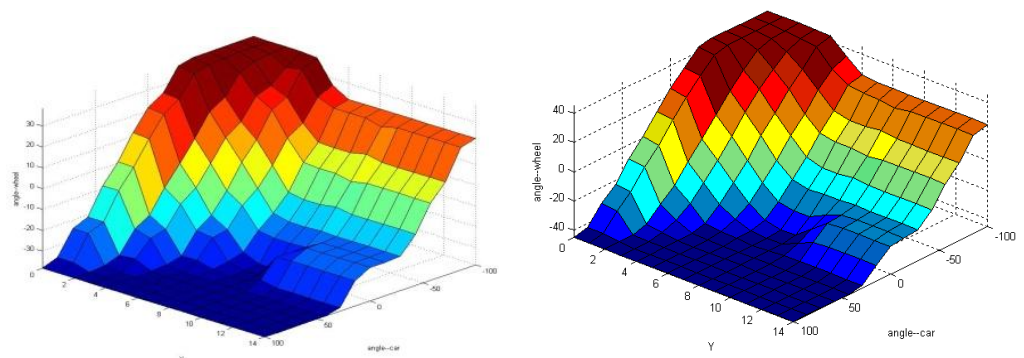

Fig 8: surface controller 2 in the state mamdani and sugeno
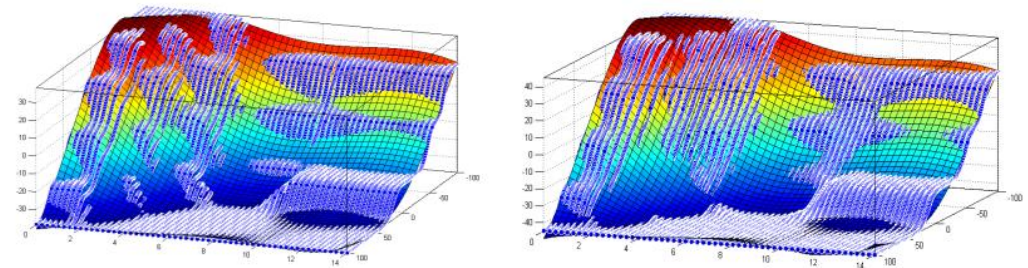

Fig 9: The Board obtained a controller 2 in order to mamdani state and sugeno state

\section{Parallel park a car from the rear:}

two fuzzy controller is used for parks. Both control methods have been used to mamdani. of the 2 fuzzy controller is used for parks.

controller 1: this controller is used to start the second controller. this controller is a single input and single output.the input of the controller of the table $(\mathrm{y} 0)$ and output the longitudinal position for the start of the second controller (xsc).

controller 2: this controller is used for both input $(\theta, \mathrm{y})$ and output $\phi$ variables.

controller 1: the membership functions and rules table is as follows .it is worth mentioning that the experimental values of membership functions are calculated. 
J. Ghobadi, A. Adine, S.K. Mousavi / TJMCS Vol .5 No.3 (2012) 167-175

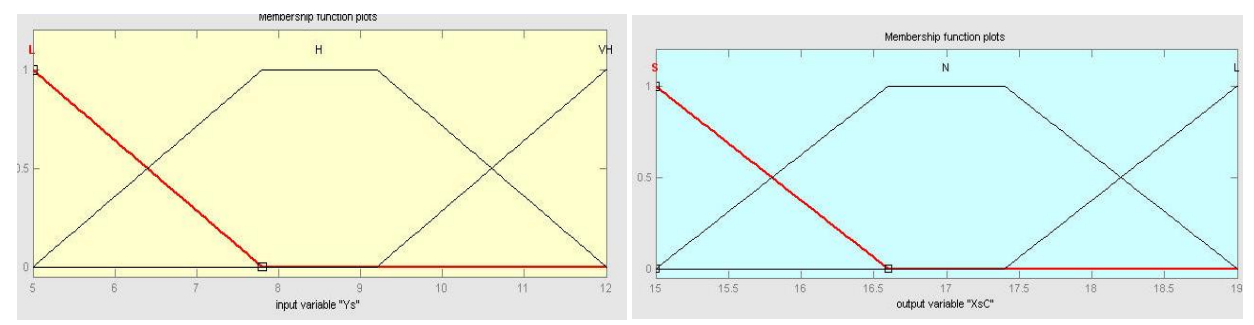

Fig 10: membership function of input and output controller 1

Table 6 - table 1 controller rules

\begin{tabular}{|c|c|c|c|}
\hline Ys & L & H & VH \\
\hline $\mathrm{XsC}$ & $\mathrm{S}$ & $\mathrm{N}$ & $\mathrm{L}$ \\
\hline
\end{tabular}
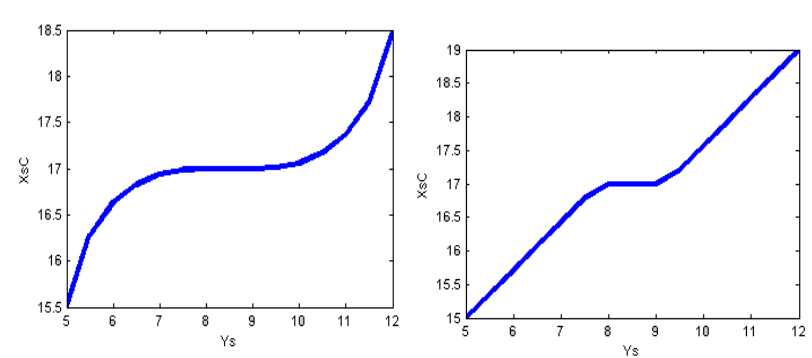

Fig 11: surface controller 1 in the state mamdani and sugeno

Table 7 - Comparison of estimated values with actual values for controller 1

\begin{tabular}{|c|c|c|c|c|}
\hline Input & $\begin{array}{c}\text { real } \\
\text { (mamdani) }\end{array}$ & $\begin{array}{c}\text { estimated } \\
\text { (mamdani) }\end{array}$ & $\begin{array}{c}\text { real } \\
\text { (sugeno) }\end{array}$ & $\begin{array}{c}\text { estimated } \\
\text { (sugeno) }\end{array}$ \\
\hline 5 & 15.5 & 15.53 & 15 & 15 \\
\hline 6 & 16.6 & 16.63 & 15.7 & 15.7 \\
\hline 80 & 17 & 16.99 & 17 & 17 \\
\hline 10 & 17.1 & 17.065 & 17.6 & 17.6 \\
\hline 12 & 18.5 & 18.471 & 19 & 19 \\
\hline
\end{tabular}
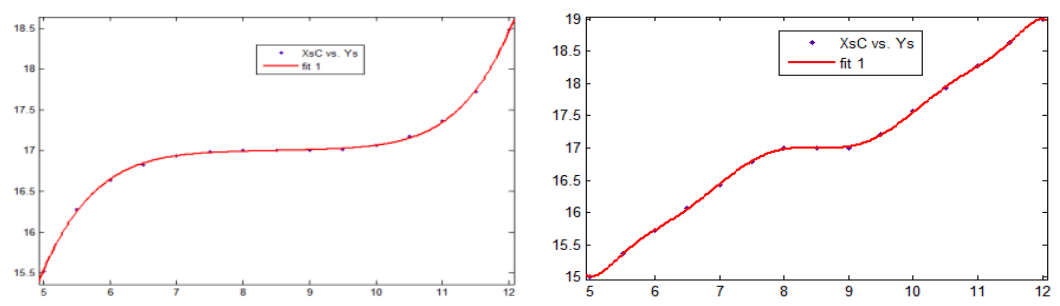

Fig 12: the equation obtained for controller 1 in the state mamdani and sugeno

Controller 2: the controller input and output membership functions similar to the previous controller has two parallel park only table rules are different.

Table 8 - Table rules controller 2

\begin{tabular}{|c|c|c|c|c|c|c|c|}
\hline & RD & RU & RH & H & LH & LU & LD \\
\hline L & Ri & NL & ZE & NR & NR & Ri & Ri \\
\hline C & Ri & NL & ZE & NR & Ri & Ri & Ri \\
\hline RC & Ri & Le & NL & ZE & NR & Ri & Ri \\
\hline NR & Ri & Le & Le & NL & ZE & NR & Ri \\
\hline R & Ri & Le & Le & Le & NL & ZE & NR \\
\hline
\end{tabular}
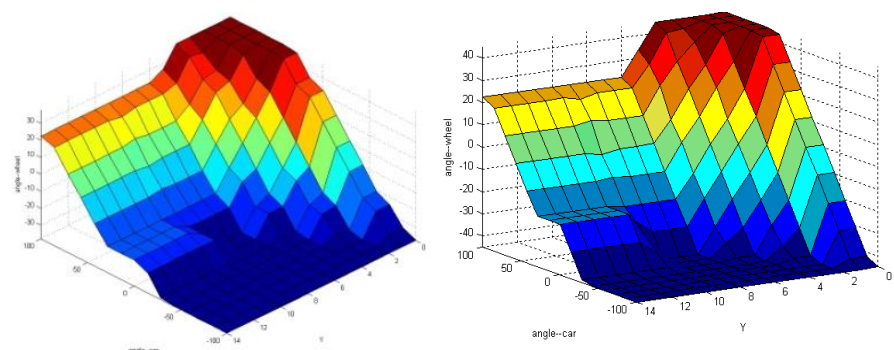

Fig 13: surface controller 2 in the state mamdani and sugeno 
J. Ghobadi, A. Adine, S.K. Mousavi / TJMCS Vol .5 No.3 (2012) 167-175

Table 9 - Comparison of estimated values with actual values for the controller 2

\begin{tabular}{|c|c|c|c|c|c|}
\hline \multirow{2}{*}{\multicolumn{2}{|c|}{ Input }} & \multirow{3}{*}{$\begin{array}{c}\text { real } \\
\text { (mamdani) }\end{array}$} & \multirow{3}{*}{$\begin{array}{l}\text { estimated } \\
\text { (mamdani) }\end{array}$} & \multirow{3}{*}{$\begin{array}{c}\text { real } \\
\text { (sugeno) }\end{array}$} & \multirow{3}{*}{$\begin{array}{l}\text { estimated } \\
\text { (sugeno) }\end{array}$} \\
\hline & & & & & \\
\hline$Y$ & $\theta$ & & & & \\
\hline 0 & 0 & 22.5 & 21.73 & 22.5 & 26.64 \\
\hline 2 & -100 & -37.8 & -37.8 & -45 & -45 \\
\hline 6 & 100 & 22.5 & 22.46 & 22.5 & 32.18 \\
\hline 10 & -50 & -37.8 & -37.08 & -45 & -43.91 \\
\hline 14 & 50 & -6.88 & -7.207 & -7.8 & -7.566 \\
\hline
\end{tabular}
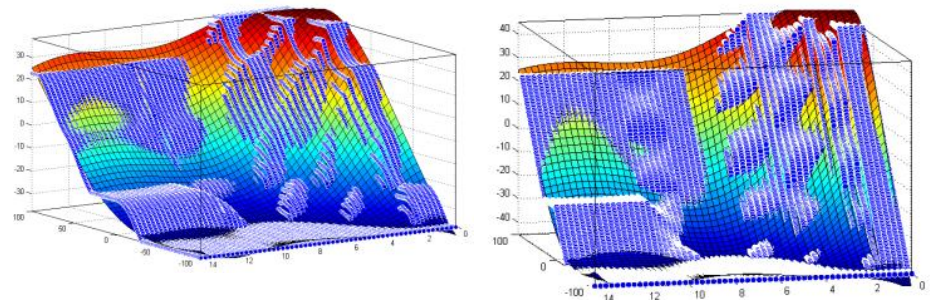

Fig 14: The Board obtained a controller 2 in order to mamdani state and sugeno state

\section{Vertical Park:}

this park is just a controller with one input and one output is used. The controller input and output angle of the vehicle's steering angle. Membership functions and rules table is as follows.
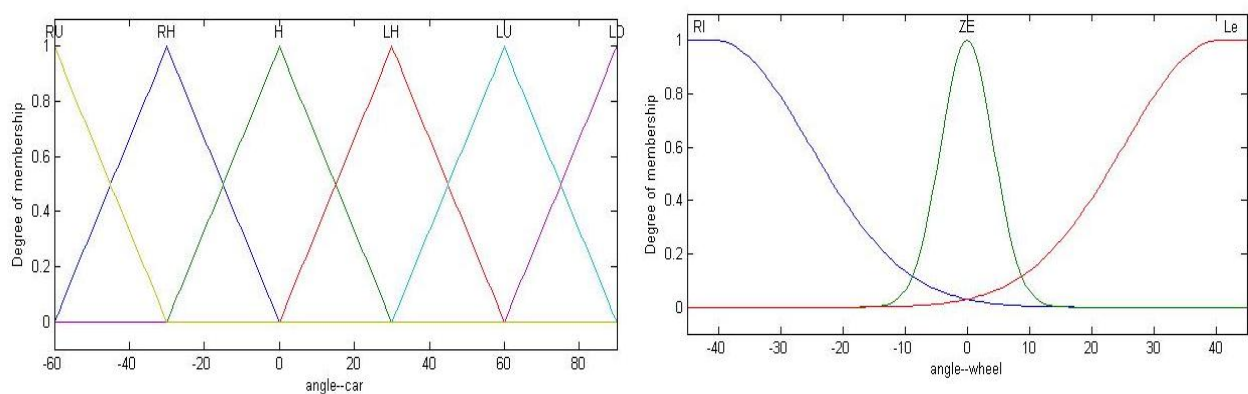

Fig 15: Input membership function controller

Table 10 - Table of controller rules

\begin{tabular}{|c|c|c|c|c|c|c|}
\hline Angle-car & $\mathrm{RU}$ & $\mathrm{RH}$ & $\mathrm{H}$ & $\mathrm{LH}$ & $\mathrm{LU}$ & $\mathrm{LD}$ \\
\hline Angle-wheel & $\mathrm{Ri}$ & $\mathrm{Ri}$ & $\mathrm{Ri}$ & $\mathrm{Ri}$ & $\mathrm{Ri}$ & ZE \\
\hline
\end{tabular}
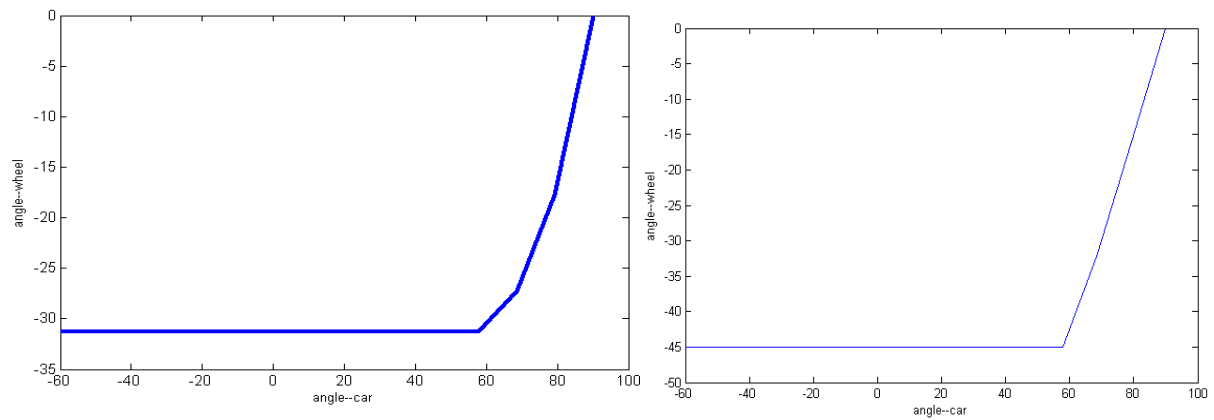

Fig 16: surface controller in the state mamdani and sugeno
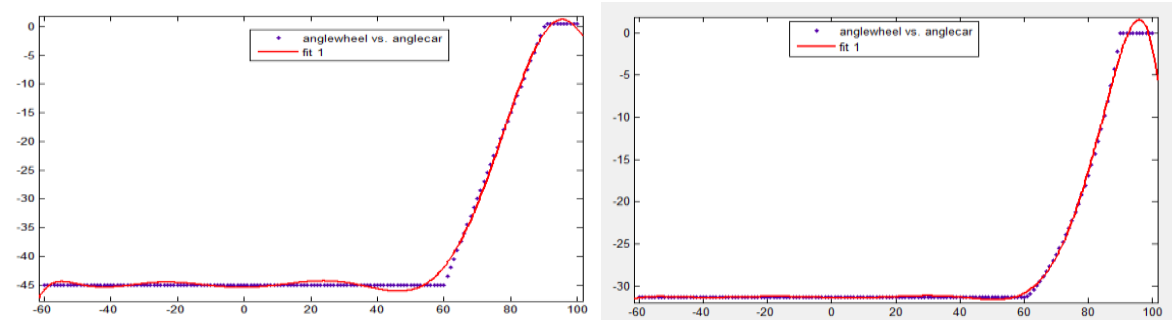

Fig 17: the equation obtained for controller 1 in the state mamdani and sugeno 
Table 11 - Comparison of estimated values with actual values for controller

\begin{tabular}{|c|c|c|c|c|}
\hline Input & $\begin{array}{c}\text { real } \\
\text { (mamdani) }\end{array}$ & $\begin{array}{c}\text { estimated } \\
\text { (mamdani) }\end{array}$ & $\begin{array}{c}\text { real } \\
\text { (sugeno) }\end{array}$ & $\begin{array}{c}\text { estimated } \\
\text { (sugeno) }\end{array}$ \\
\hline 20 & -31.3 & -31.26 & -45 & -44.23 \\
\hline 40 & -31.3 & -31.32 & -45 & -45.69 \\
\hline 60 & -31.3 & -30.82 & -45 & -41.9 \\
\hline 80 & -16.9 & -16.41 & -15 & -14.8 \\
\hline 100 & 0 & -1.9 & 0 & -0.426 \\
\hline
\end{tabular}

\section{Simulation results:}

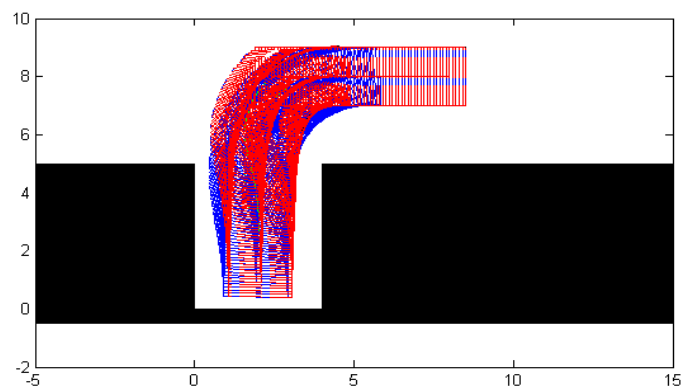

Fig 18: Simulation of vertical car park with the initial position $(8,8)$, the red (Sugeno) and the blue (mamdani)

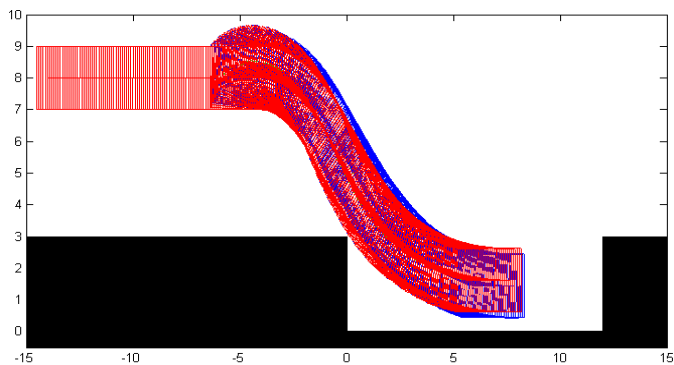

Fig 19: Simulation of the front car park parallel with the primary position $(-12,8)$ The red (Sugeno) and the blue (mamdani)

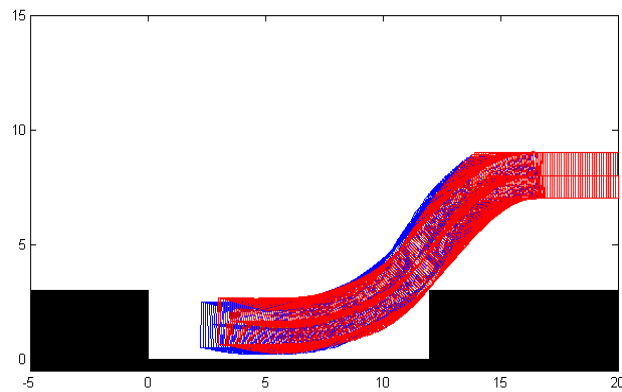

Fig 20: Simulation of the rear car park parallel with the primary position $(8,18)$, the red (Sugeno) and the blue (mamdani)

\section{Conclusion:}

this method is simple but efficient controller to controller such that only the fuzzy controller is used. However, other methods of neural networks, genetic algorithms and image processing in terms of better efficiency of this method but have a complex structure. Top of the simulations, it is seen that there is little difference between the Sugeno obtain and can be said that with the correct output values for the Sugeno controller can control the behavior is similar to mamdani.

\section{References:}

[1] R. M. DeSantis, R. Hurteau, O. Alboui, B. Lesot: Experimental Stabilization of Tractor and TractorTrailer like Vehicles, Proc. of the 2002 IEEE Int. Sym. on Intelligent Ctrl., p. 188-193, 2002.

[2] W. Young, R.G. Thompson, M.A.P. Taylor, A review of urban parking models. Transport Reviews $11,6384,1991$

[3] R. Arnott, J. Rowse, Modeling parking. Journal of Urban Economic, 1999.

[4] C. Ahrikencheikh and A. Seireg: “Optimized-Motion Planning”, John Wiley \& Sons, 1994. 
[5] T.-H. S. Li, S. J. Chang: Autonomous Fuzzy Parking Control of a Car-like Mobile Robot, IEEE Trans. Sys. Man \& Cyb. Part A, v 33, n 4, p 451-465, July, 2003.s 45, 97-124.

[6] I. E. Paromtchik and C. Laugire, Motion generation and control for parking an autonomous vehicle, in: Proc. of '96 IEEE Conf. on Robotics and Automation, Vol. 4, Minneapolis, MN, 1996, pp. 3117-3122.

[7] D. Teodorovic, P. Lucic Intelligent parking systems, European Journal of Operational Research , Volume 175, Issue 3 , 16 December 2006, Pages 1666-1681

[8] S.C. Wong, C.O. Tong, W.C.H. Lam, R.Y.C. Fung, Development of parking demand models in Hong Kong. Journal of Urban Planning and development-ASCE 126, 55-74, 2000.

[9] J. Polak, K.W. Axhausen, Parking search behavior: A review of current research and future prospects. Transport Studies Units, Working Paper 540, Oxford University, 1990.

[10] B.J. Waterson, N.B. Hounsell, K. Chatterjee, Quantifying the potential savings in travel time resulting from parking guidance systems - a simulation case study. Journal of the Operational Research Society 10, 1067-1077, 2001.

[11] L.X. Wang, J.M. Mendel, Generating fuzzy rules by learning from examples. IEEE Transactions on Systems, Man and Cybernetics 22, 1414-1427, 1992.

[12] R. M. Murray and S. S. Sastry, Nonholonomic motion planning: Steering using sinusoids, IEEE Trans. Automat. Control 4 (1993), 700-716.

[13] S. Achiche, L. Baron, and M. Balazinski, : "Real/Binary-Like Coded Versus Binary Coded Genetic Algorithms to Automaticall Generate Fuzzy Knowledge Bases: A comparative study, Engineering Applications of Artificial Intelligence, 17, 4, pp. 313-325, June 2004.

[14] W. A. Daxwanger and G. K. Schmidt, "Skill-based visual parking control using neural and fuzzy networks," in Proc. IEEE Int. Conf. System, Man, Cybernetics, vol. 2, 1995, pp. 1659-1664.

[15] D. Gorinevsky, A. Kapitanovsky, A. Goldenberg: Neural network architecture for trajectory generation and control of automated car parking, IEEE Transactions on Control Systems Technology, v 4, n 1, Jan, 1996, p 50-56

[16] R. J. Oentaryo, and M. Pasquier, "Self-Trained Automated Parking System," in 2004 8th International Conference on Control, Automation, Robotics and Vision (ICARCV) 2004

[17] A. KHOUKHI, L. BARON, M. BALAZINSKI: Fuzzy Parking Manoeuvres of Wheeled Mobile Robots 1-4244-1214-5/07/\$25.00 (C2007 IEE

[18] Chen-Kui Lee , Chun-Liang Lin , Bing-Min Shiu : Autonomous Vehicle Parking Using Artificial Intelligent Approach 978-1-4244-2713-0/09/\$25.00 (C)2009 IEEE

[19] Benjamas Panomruttanarug, Sarayut Tungporntawee, Parnupong Thongsuk, and Kohji Higuchi : An Emulation of Autonomous Parallel Parking System Using Fuzzy Logic Control PR0002/09/0000-4548 $¥ 400$ (C) 2009 SICE

[20] Zhi-Long Wang, Chih-Hsiung Yang, Tong-Yi Guo : The Design of An Autonomous Parallel Parking Neuro-Fuzzy Controller for A Car-like Mobile Robot PR0001/10/0000-2593 ¥400 (C) 2010 SICE 